\title{
Demographic Patterns and Limitation of Grey Wolves, Canis lupus, in and Near Pukaskwa National Park, Ontario
}

\author{
S. Anne Forshner ${ }^{1,2}$, Paul C. Paquet ${ }^{3}$, Frank G. M. Burrows ${ }^{4}$, Graham K. Neale ${ }^{5}$, Keith D. Wade ${ }^{6}$, \\ and William M. SAMUEL
}

${ }^{1}$ Department of Biological Sciences, University of Alberta, Edmonton, Alberta T6G 2E9 Canada

${ }^{2}$ Mailing address: P.O. Box 10, Jasper National Park, Jasper, Alberta T0E 1E0 Canada

${ }^{3}$ Faculty of Environmental Design, University of Calgary, Calgary, Alberta T2N 1N4 Canada

${ }^{4}$ Bruce Peninsula National Park, Tobermory, Ontario NOH 2R0 Canada

${ }^{5}$ Garcia and Associates, Bozeman, Montana 59718 USA

${ }^{6}$ Pukaskwa National Park, Heron Bay, Ontario P0T 1R0 Canada

Forshner, S. Anne, Paul C. Paquet, Frank G. M. Burrows, Graham K. Neale, Keith D. Wade, and William M. Samuel. 2003. Demographic patterns and limitation of Grey Wolves, Canis lupus, in and near Pukaskwa National Park, Ontario. Canadian Field Naturalist 118(1): 95-104.

In response to concern regarding the growth and long-term viability of the wolf population in and near Pukaskwa National Park, a study of demographic patterns and limitation of radio-collared wolves (Canis lupus) was completed between 1994 and 1998. The mean annual finite rate of increase (0.96) suggested that population growth of wolves was limited and declining slightly. Small pack sizes, high cumulative mortality, and low reproductive success also suggested a declining population. Two limiting factors, ungulate biomass and human-caused mortality, were examined to determine the importance of each in limiting the population growth of wolves. Ungulate biomass was involved because occurrence of natural-caused mortality was high (9 of 17 wolves) compared with other studies. In addition, consumption rates were low and similar to other studies where starvation and other signs of malnutrition were noted. Further, Moose densities in the study area were low to moderate and below thresholds indicating nutritional stress for wolves. Occurrence of human-caused mortality was high ( 8 of 17 wolves) suggesting that it was also an important limiting factor, particularly given the low availability of ungulate biomass and reproduction noted in this study. Based on present demographic patterns, ungulate biomass, and human-caused mortality, the wolf population likely will remain at present low densities or continue to decline.

Key Words: Canis lupus, wolves, limitation, demographic patterns, Pukaskwa National Park, Ontario.

In 1996, researchers in the Greater Pukaskwa Ecosystem (GPE) (Figure 1) in Ontario postulated that two limiting factors were negatively affecting the growth and long-term viability of the Grey Wolf (Canis lupus) population (Burrows et al. 1996*). These limiting factors were low availability of ungulate prey and high mortality from human causes. Managers in Parks Canada Agency were concerned because wolves are a native species in the GPE. Thus, Parks is legislated to protect and further, to ensure the long-term viability of that population (Parks Canada 2000). This prompted a study of wolves in the western half of the GPE, including Pukaskwa National Park (PNP).

In this paper, we quantify population limitation of wolves and examine the importance of ungulate biomass and human-caused mortality in limiting the population growth of wolves, 1994-1998. For these purposes, we review and discuss demographic data on wolf densities, population growth, reproduction, and mortality. Further, we report and discuss data on the availability of prey and rates of kill and consumption.

\footnotetext{
* References marked with asterix (*) are listed in a separate Documents Cited section following Acknowledgements, all others are in Literature Cited.
}

\section{Study Area}

The study area comprised $4500 \mathrm{~km}^{2}$ in the western half of the GPE on the north shore of Lake Superior in Ontario $\left(48^{\circ} \mathrm{N}\right.$ and $\left.85^{\circ} \mathrm{W}\right)$ (Figure 1). The area includes PNP $\left(1878 \mathrm{~km}^{2}\right)$ but also adjacent land with intensive forestry, gold mines, towns and associated infrastructure.

Two distinct physiographic regions, coastal and interior, occur within the study area. The coastal region is characterized by rugged topography with elevations ranging from 189 to $650 \mathrm{~m}$. Many lakes and rivers occur in the area, creating a patchy landscape. The interior region is a flat plateau characterized by a heavily eroded landscape of mountains previously scoured by continental glaciers (Poitevin et al. 1989*).

Mean annual precipitation is $74 \mathrm{~cm}$ along the coast and $64 \mathrm{~cm}$ inland. Winter and summer temperatures range from $-13 \mathrm{C}^{\circ}-14.6 \mathrm{C}^{\circ}$ for the coastal area and $-17 C^{\circ}-15.9 C^{\circ}$ inland (Poitevin et al. 1989*). Ice cover on Lake Superior ranges annually from $5-100 \%$ (Skibicki 1994*).

Vegetation on the coast along Lake Superior and inland is mixed with associations of Balsam Fir (Abies balsamea), Jack Pine (Pinus banksiana), White Birch (Betula papyrifera), White Spruce (Picea glauca), Black Spruce (Picea mariana), Eastern White Cedar 


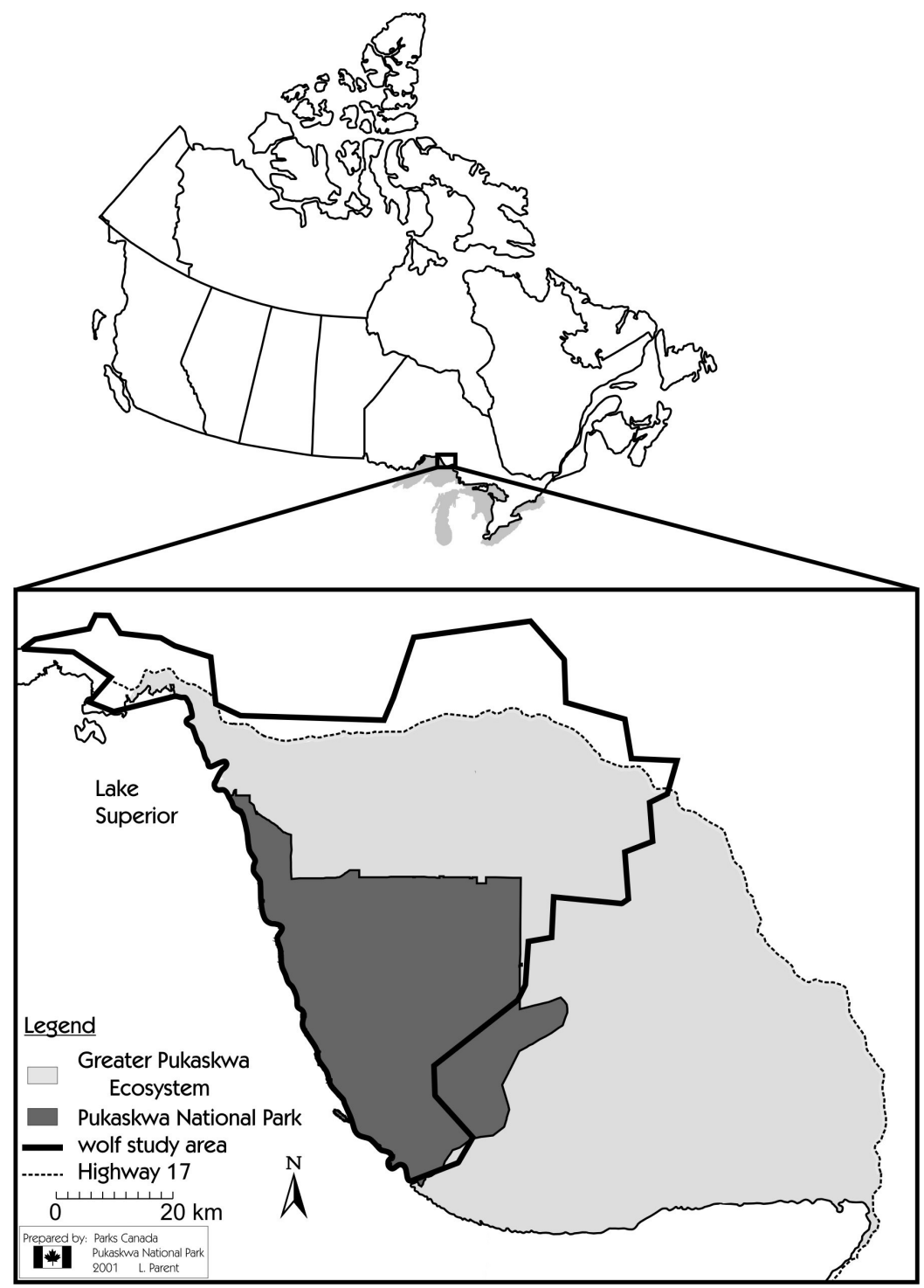

FIGURE 1. Location of the wolf (Canis lupus) study area within the Greater Pukaskwa Ecosystem, Ontario, Canada (center $\left.48^{\circ} \mathrm{N}, 85^{\circ} \mathrm{W}\right)$.

(Thuja occidentalis), and Trembling Aspen (Populus tremuloides), with occasional Red Maple (Acer rubrum) and other hardwoods more locally abundant in the southeastern corner of the study area.

Predatory mammals included Grey Wolf, Black Bear (Ursus americanus), Red Fox (Vulpes vulpes), Lynx (Lynx canadensis), River Otter (Lontra canadensis), Fisher (Martes pennanti), American Marten (Martes americana), Mink (Mustela vison), and Weasels (Mustela spp.). Coyotes (Canis latrans) were rare except around towns.

Moose (Alces alces) were the primary and most abundant ungulate prey species for wolves. Woodland
Caribou (Rangifer tarandus tarandus) were few and concentrated in small bands along the coast of Lake Superior (Bergerud 1985). Numbers ranged from 6-14 in PNP, 1993-1997 (Wade 1993*, 1995*, 1997*, 1999*). White-tailed Deer (Odocoileus virginianus) were rare in the GPE.

\section{Methods}

Capture and handling

We attempted to locate wolves in as many packs as possible. Wolves were captured with modified leghold traps in summer $(n=21)$ and by using a net-gun from a helicopter in early winter $(n=5)$. All wolves 


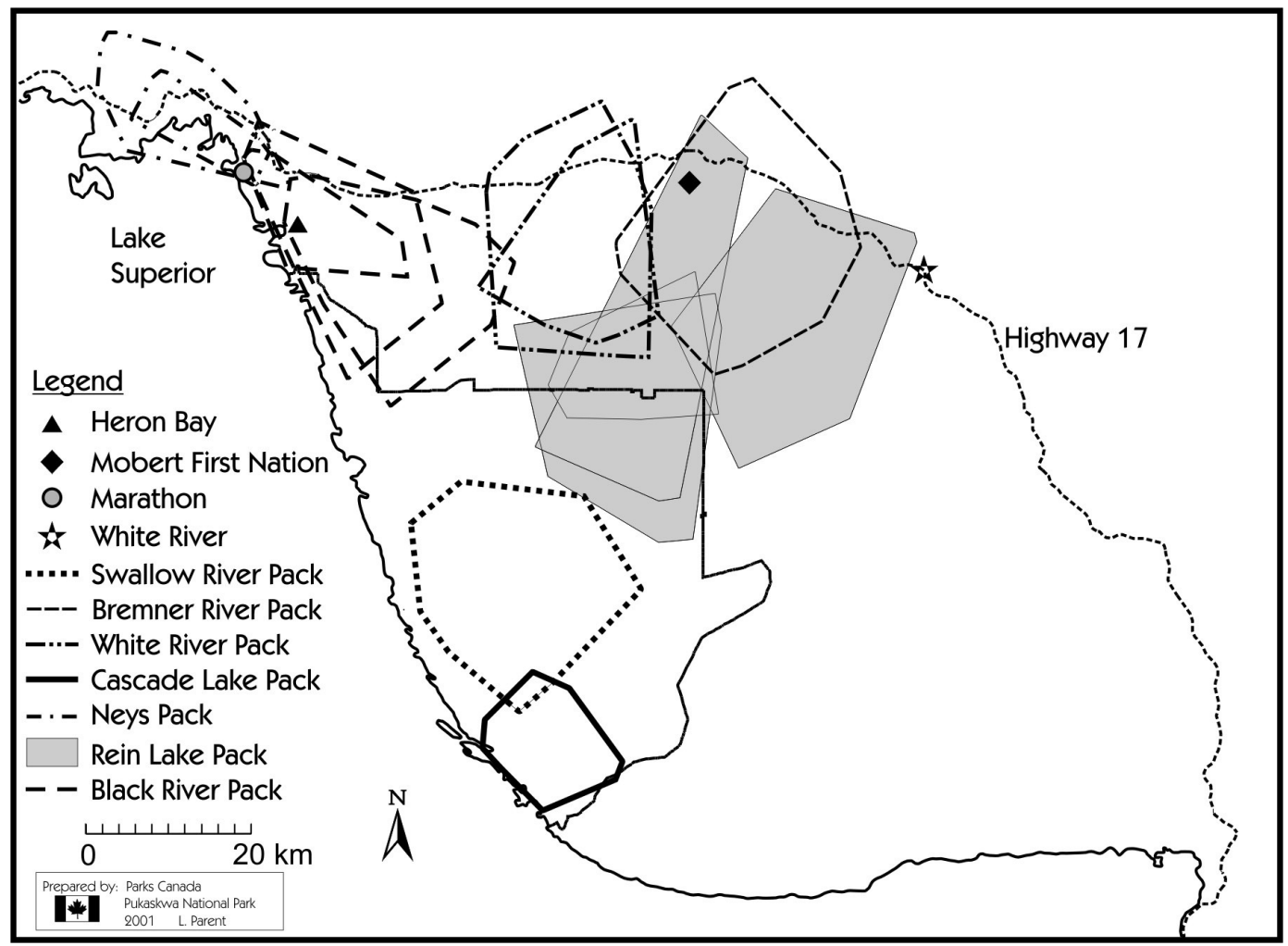

FIGURE 2. Annual (1 April - 31 March) home ranges of wolves in the study area, 1994-1998. Home ranges are 95\% MCP. Years for home ranges of packs were Swallow and Bremner River Packs, 1997-1998; White River Pack, 1996-1998; Cascade Lake Pack, 1995-1996; Neys Pack, 1995-1997; Rein Lake Pack, 1994-1998; Black River Pack, 1994-1996, 1997-1998.

were immobilized with Telazol ${ }^{\circledR}$ (tiletamine hydrochloride (HCL) and zolazepam HCL, A.H. Robins Co., Richmond, Virginia). Rectal temperature, pulse, and respiration of wolves were closely monitored throughout the procedure. Immobilized wolves were examined for injuries, equipped with conventional VHF transmitters (Lotek ${ }^{\circledR}$, Newmarket, ON), weighed, sexed, and aged. A committee for care of wild animals approved all capture and handling operations (Wildlife Animal Care Committee, Ontario Ministry of Natural Resources, 1994-1997).

\section{Biotelemetry}

The target frequency for locating each radio-collared wolf was four times/month in summer (April-October) and six to eight times/month in winter (November-March). Wolves were located by plane using a portable receiver (Lotek ${ }^{\circledR}$ SRX-400), right-left switch boxes, and paired three-element Yagi antennae mounted on the wing struts of a fixed-wing aircraft (Cessna 185). Wolf location was recorded with a Global Positioning System (Garmin ${ }^{\circledR} 75$ Aviation). For all locations, transmitter frequency, observer, date, time of location, number of wolves, color of wolves, and pre- sence of pups were recorded. Mean error of telemetry (difference between observed and true location) was calculated by using data we collected when regularly locating stationary transmitters placed throughout the study area. Location data were downloaded into a Geographical Information System (GIS [Tydac SPANS $\left.{ }^{\circledR}\right]$ ) for display and analysis of wolf movements.

\section{Home Ranges}

Ranges $\mathrm{V}^{\circledR}$ software (Kenward and Hodder 1996*) was used to calculate annual (1 April - 31 March) sizes of home ranges. To represent these areas we used relocations of packs and $95 \%$ minimum convex polygons (MCP) (Mohr 1947). All obvious extraterritorial forays and dispersals were excluded from the analyses (Ballard et al. 1997). We assumed home ranges were defined when the observation-area curve formed an asymptote (Kenward and Hodder 1996*) and locations were obtained throughout the year.

For each pack we used one radio-collared wolf/year to represent the annual home range of the pack. This is reasonable as locations from one wolf indicate position of the entire pack when a high degree of association exists among pack members (Kolenosky 
and Johnston 1967; Fuller and Keith 1980; Fritts and Mech 1981; Ciucci et al. 1997). This condition was confirmed in this study by aerial observations of packs during telemetry flights.

Accuracy of locations for the entire study was $150 \mathrm{~m}$, which was the mean error of telemetry obtained by all participants. Accordingly, we changed the fix resolution from the Ranges $\mathrm{V}^{\circledR}$ default of $1 \mathrm{~m}$ to $150 \mathrm{~m}$. This resolution was used to set the width of the boundary strip that was included in polygon edges and areas (Kenward and Hodder 1996*). We left the scaling parameter at the software default of $1 \mathrm{~m}$, which means that each coordinate unit was $1 \mathrm{~m}$ from the next.

\section{Density, pack sizes, and population growth}

Density of wolves $/ 1000 \mathrm{~km}^{2}$ was calculated by determining intra-pack densities (number of wolves in pack/home range size) and averaging these densities/year (Potvin 1987; Bjorge and Gunson 1989; Okarma et al. 1998). The number of wolves in a pack was based on the maximum number of wolves observed in mid-winter (15 January-15 February). We defined a pack as a group of two or more wolves that traveled together for more than one month (Messier 1984). In two cases we had insufficient data to determine the sizes of home ranges, thus we followed Messier (1985) and used data from previous or subsequent years.

Population growth or the mean annual finite rate of increase was calculated based on the ratio of successive yearly estimates of density (Fuller 1989).

\section{Reproduction}

We did not observe wolves at dens during this study. Dense vegetation and the secretive nature of wolves precluded accurate visuals of wolf groups until October or November, at which time pups were difficult to distinguish physically from adults. Hence, successful year-specific reproduction was ascertained when: (1) pups were captured in spring; or (2) a pack increased in size from March to the following December, providing that sites of focal activities (e.g., pup-resting areas) were observed in the intervening time (Messier 1985). Unsuccessful reproduction (i.e., no or failed reproduction) was ascertained when: (1) a pack did not demonstrate focal activity sites in the summer; or (2) a pair remained together from March to the following December (Messier 1985). Results are reported for each pack by year.

\section{Moose density}

To examine availability of ungulate biomass to wolves, we used Moose density (moose $/ 1000 \mathrm{~km}^{2}$ ) based on aerial surveys using stratified random sampling (Gasaway et al. 1986*). More specifically, from 1993 to 1999 a single Moose density was calculated for PNP and the three Wildlife Management Units (21A, 21B, 33) surrounding PNP where wolf packs were distributed. There was little or no change in Moose density among yearly estimates (Burrows 2001), thus we averaged results from 1993-1999 for each area.

\section{Rates of kill and consumption of prey by wolves}

The rates of killing and consumption of large prey by wolves in four packs were studied by daily aerial and ground observation, January-March 1998. The Bremner River Pack was located 57 times between 18 January and 27 March 1998 (69 days) and the Rein Lake Pack was located 57 times between 8 January and 26 March 1998 (79 days). Other packs located were the White River Pack, 22 times between 11 February and 20 March 1998 (38 days) and the Swallow River Pack, 22 times between 9 February and 22 March 1998 (42 days). To calculate the kill rate, we recorded the number of animals killed by wolves/ tracking period and the number of wolves present at the kill (Messier 1985). Prey killed were located from the air and from ground-based tracking. At kill sites, we confirmed prey species, time, and cause of death. For only the largest pack of wolves (Bremner River), in addition to aerial locations, we simultaneously snow-tracked wolf movements and collected scats to determine if all kill sites were found with the aerial telemetry. Technicians at Big Sky Laboratory (PO Box 0776, Florence, Montana 59833-0776) identified prey remains by macroscopic examination and comparison with known material and hair-scale impressions (Adorjan and Kolenosky 1969*).

In this analysis we considered only tracking sessions where pack locations were not separated by $>54 \mathrm{hr}$. There were a few exceptions, however, where locations were separated by $72 \mathrm{hr}$. These periods were retained in the analysis because wolves made a kill or visited one of several garbage dumps the day they were relocated making it unlikely that we missed a kill. Nonetheless, kill rates in this study should be considered minimums as wolves were not relocated every day and some small prey such as deer (fawns and adults), Caribou calves, Beaver, and other smaller prey items may have been missed. It is unlikely, however, that we missed many of these kills because White-tailed Deer and Caribou were rare in the study area. We report kill rates as ungulates killed/wolf/day.

Rates of consumption were calculated based on kill rates and average weights of wolves and prey. We calculated the whole weight of wolves based on the average from radio-collared adults and other wolves found dead in the study area. The average edible weights of Moose and beaver prey were assumed to be 330, 261, 114, and $13 \mathrm{~kg}$ for adult male Moose, adult female Moose, young-of-the-year Moose and Beaver, respectively (Peterson 1977; Thurber and Peterson 1993). We assumed the average weight of a White-tailed Deer was $105 \mathrm{~kg}$ for an adult male (Kolenosky 1972; Forbes and Theberge 1996). Eighty \% of the adult deer carcass was considered edible (Pimlott 1967; Forbes and Theberge 1996). All consumption rates are reported as $\mathrm{kg}$ prey $/ \mathrm{kg}$ wolf $/$ day. 
TABLE 1. Sizes of annual home ranges and home range areas/wolf of seven packs of Grey Wolves (Canis lupus) in the study area, 1994-1998.

\begin{tabular}{|c|c|c|c|c|c|c|c|}
\hline Year & Pack & $\begin{array}{c}\text { Early } \\
\text { winter } \\
\text { number } \\
\text { of wolves } \\
\text { in pack }\end{array}$ & $\begin{array}{c}\text { Late } \\
\text { winter } \\
\text { number } \\
\text { of wolves } \\
\text { in pack }\end{array}$ & $\begin{array}{l}100 \% \\
\mathrm{MCP} \\
\left(\mathrm{km}^{2}\right)^{\mathrm{c}}\end{array}$ & $\begin{array}{c}95 \% \\
\mathrm{MCP} \\
\left(\mathrm{km}^{2}\right)^{\mathrm{c}} \\
\end{array}$ & $\begin{array}{c}\text { Number } \\
\text { of radio } \\
\text { fixes }\end{array}$ & $\begin{array}{c}\text { Area/wolf } \\
\left(\mathrm{km}^{2}\right)^{\mathrm{d}}\end{array}$ \\
\hline \multirow[t]{2}{*}{ 1994-1995 } & Black River ${ }^{\mathrm{e}}$ & 6 & 4 & 283 & 156 & 53 & 26 \\
\hline & Rein Lake & 3 & 3 & 310 & 249 & 38 & 83 \\
\hline \multirow[t]{4}{*}{ 1995-1996 } & Black River ${ }^{\mathrm{e}}$ & 4 & 4 & 548 & 388 & 55 & 97 \\
\hline & Rein Lake & 3 & 3 & 600 & 533 & 58 & 178 \\
\hline & Neys ${ }^{\mathrm{e}}$ & 3 & 4 & 269 & 244 & 96 & 81 \\
\hline & Cascade Lake ${ }^{\mathrm{f}}$ & 1 & 1 & 204 & 170 & 26 & 170 \\
\hline \multirow[t]{3}{*}{ 1996-1997 } & Rein Lake & 2 & 1 & 561 & 557 & 39 & 279 \\
\hline & Neys ${ }^{\mathrm{e}}$ & 6 & 4 & 113 & 101 & 96 & 17 \\
\hline & White River & 2 & 2 & 407 & 345 & 37 & 173 \\
\hline \multirow[t]{7}{*}{ 1997-1998 } & Black River ${ }^{\mathrm{e}}$ & 4 & 3 & 468 & 450 & 74 & 113 \\
\hline & Rein Lake & 2 & 1 & 692 & 600 & 87 & 300 \\
\hline & White River & 2 & 2 & 589 & 498 & 65 & 249 \\
\hline & Bremner River & 6 & 3 & 760 & 644 & 93 & 107 \\
\hline & Swallow River & 5 & 3 & 567 & 500 & 62 & 100 \\
\hline & Mean & 3.5 & 2.7 & 455 & 388 & 63 & 139 \\
\hline & SE & 0.5 & 0.3 & 52 & 48 & 6.3 & 25 \\
\hline
\end{tabular}

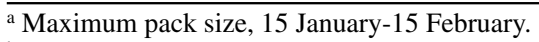

${ }^{\mathrm{b}}$ Maximum pack size, March.

${ }^{\mathrm{c}}$ Sizes of home ranges were described using the minimum convex polygon method (MCP) (Mohr 1947).

${ }^{\mathrm{d}}$ Based on $95 \%$ MCP.

${ }^{\mathrm{e}}$ Packs that used town dumps.

${ }^{\mathrm{f}}$ Home range size and home range area/wolf were not included in mean because the areas were not fully defined; i.e., the observation-area curve was asymptotic but locations were not obtained throughout the year.

\section{Mortality and survival of radio-collared wolves}

We completed survival analysis for radio-collared wolves from 20 August 1994 to 31 December 1998. Wolves were re-located from time of capture until mortality or the radio-signal disappeared. For known deaths we estimated the date of mortality to the nearest day using evidence from the field. When evidence was unavailable, day of mortality was deemed the midpoint of the interval between the last day the wolf was known alive and the day it was discovered dead. The cause of mortality was often identified on site and when possible, confirmed by necropsy.

We calculated the cumulative mortality of radiocollared wolves $(n=25)$ using the Kaplan-Meier product limit estimator and Minitab (Version 12) software. One of 26 captured wolves was shot by a trapper while in the research trap and is not included in the analysis. Cause of mortality was described using $\%$. We assumed the proximate cause of death was the ultimate cause of death. We were unable to assess the relative importance of other factors that may have been involved.

\section{Results}

Twenty-six adult wolves were captured and then radio-collared $(n=25)$ or tagged $(n=1)$ from 19941997. These animals represented seven packs and one lone wolf. Two of seven packs occurred almost exclusively in the park and all wolf packs were radiocollared in the study area. There were no other wolf packs in the study area during this study. We followed two packs in 1994-1995, four in 1995-1996, four in 1996-1997, and six in 1997-1998. The average mass of adult female wolves $(n=11)$ was $26.9 \pm 1.4 \mathrm{~kg}$ and that of adult males $(n=14)$ was $36.5 \pm 2.8 \mathrm{~kg}$.

\section{Home ranges}

Sizes of annual home ranges (Figure 2) of seven packs across 13 pack-years were adequately described in this study (Table 1). Estimates accurately represented areas used by wolves because sizes of annual home ranges were not correlated with number of relocations $\left(\mathrm{r}_{\mathrm{s}}=0.52,0.05>P>0.02\right)$. Home range sizes of packs and home range areas/wolf were variable. The average annual home range size was $388 \pm$ SE $48 \mathrm{~km}^{2}\left(95 \% \mathrm{MCP}, n=13\right.$, range $\left.=101-644 \mathrm{~km}^{2}\right)$ 
(Table 1). The average home range area/wolf was $139 \pm$ SE $25 \mathrm{~km}^{2}$ (95\% MCP, $n=13$, range $=17-300$ $\left.\mathrm{km}^{2}\right)$ (Table 1).

Density, pack sizes, and population growth

Wolf density did not change over time; recorded densities were $7.9,9.6$, and 7.2 wolves $/ 1000 \mathrm{~km}^{2}$ in 1995-1996 ( $n=4$ packs), 1996-1997 $(n=4)$, and 1997$1998(n=6)$, respectively. Density declines, however, if the Neys pack (Figure 2) is excluded from the calculations. This pack exclusively used dumps for food (Krizan 1997) and the home range was much smaller compared with all other packs in the study (Table 1). Accordingly, wolf densities were 7.1, 5.9, and 5.9 wolves $/ 1000 \mathrm{~km}^{2}$ in $1995-1996(n=3$ packs $)$, 1996-1997 $(n=3)$, and 1997-1998 $(n=5)$.

Average mid-winter (15 January - 15 February) pack size was $3.5 \pm$ SE 0.5 wolves $(n=14$ pack-years) (Table 1). This average declined in late winter (March) to $2.7 \pm \mathrm{SE} 0.3$ ( $n=14$ pack-years). The number of wolves in all except two packs remained stable or declined, 1994-1998. Numbers fluctuated annually in the Neys and Swallow River Packs (Table 2). Accordingly, the mean annual finite rate of increase from 1995-1998 was 0.96 .

\section{Reproduction}

From spring 1994 to spring 1998, wolves reproduced successfully in eight of 22 pack-years (36\%) (Table 3 ). This was a maximum estimate of successful reproduction. In two of eight pack-years, we assumed wolves had reproduced because large numbers of wolves were noted in the packs in the following early fall and winter.

\section{Moose density}

Average densities of Moose varied among management units. Management Unit 33 had the highest Moose density $\left(0.285 \pm 0.03-0.07 \mathrm{moose} / \mathrm{km}^{2} 90 \% \mathrm{CI}\right)$ followed by Unit 21A $(0.225 \pm 0.02-0.03), 21 \mathrm{~B}$ $(0.220 \pm 0.02-0.03)$, and PNP (0.153 $\pm 0.03-0.08)$.

\section{Rates of kill and consumption}

The Swallow River (3 wolves) and Bremner River Packs (5) killed and consumed more ungulates than the White River (2) and Rein Lake Packs (2). The kill rates for each pack respectively were $6.8,3.4,0.0$, and 0.0 ungulates/wolf/day. Consumption rates were 0.21 , $0.11,0.0$, and $0.0 \mathrm{~kg}$ prey $/ \mathrm{kg}$ wolf/day. The White River and Rein Lake Packs did not kill any ungulates; however, both packs scavenged from various sources. The White River Pack scavenged from Moose that were killed by vehicles or trains, from other wolf kills, and from snare sets. The Rein Lake Pack scavenged from refuse in the town dump for White River (Figure 2).

\section{Mortality and survival of radio-collared wolves}

As of 31 December 1998, 17 of 26 wolves radiocollared or tagged from 1994 to 1998 were dead, only four were confirmed alive, and five were missing. Eight wolves died from human causes: trains killed three,
TABLE 2. Highest numbers of wolves in packs in the study area, 1994-1998. The number of sightings is in parentheses.

\begin{tabular}{lccccc}
\hline \hline & \multicolumn{5}{c}{ Pack size $^{\mathrm{a}}$} \\
\cline { 2 - 6 } Pack & 1994 & 1995 & 1996 & 1997 & 1998 \\
\hline Rein Lake & $3(4)$ & $3(3)$ & $1(2)$ & $1^{\mathrm{b}}$ & 0 \\
White River & $2(2)^{\mathrm{b}}$ & $2(4)$ & $2(2)$ & $2(9)$ & $2(2)$ \\
Bremner River & & & & $3(3)^{\mathrm{b}}$ & \\
Cascade River & & $1(4)$ & 0 & & \\
Black River & $4(2)$ & $4(2)$ & $4(2)$ & $3(4)$ & \\
Swallow River & & & $5(2)^{\mathrm{b}}$ & $3(3)$ & $4(1)$ \\
Neys & & $3(4)$ & $4(2)$ & $2(2)$ & $4(2)$ \\
\hline \hline
\end{tabular}

${ }^{\text {a }}$ Maximum numbers of wolves seen in March.

${ }^{\mathrm{b}}$ Pack sizes were confirmed by track-counts made from the ground.

TABLE 3. Reproductive success of wolf packs, 1994-1998.

\begin{tabular}{lccccc}
\hline \hline & \multicolumn{5}{c}{ Year } \\
\cline { 2 - 6 } Pack & 1994 & 1995 & 1996 & 1997 & 1998 \\
\hline Black River & $+^{\mathrm{a}}$ & $-^{\mathrm{a}}$ & - & + & + \\
White River & $+^{\mathrm{b}}$ & - & - & - & - \\
Rein Lake & $+^{\mathrm{b}}$ & - & - & - & - \\
Neys & & & + & - & $?$ \\
Bremner River & & & & + & + \\
Swallow River & & & & - & - \\
\hline \hline
\end{tabular}

${ }^{\mathrm{a}}+=$ reproduced successfully; $-=$ did not reproduce successfully.

b This pack likely reproduced successfully because many wolves (10) were seen in late fall (November - December).

three were snared, and two shot. Nine wolves died from natural causes: two starved, two were killed by other wolves, four died from disease (three from mange and one from blastomycosis), and one died from unknown natural causes. We assumed this last wolf was not killed by humans because we were in a remote area, there were no signs of humans in the area, and we found no bullets, snares, or other human devices. Survival of radio-collared wolves decreased between one and three years post-collaring. Wolves had a 32\% (SE 0.10) chance of dying in the first year, a $30 \%$ (SE 0.15 ) chance of dying in the second year, and a $57 \%$ (SE 0.26) chance of dying in the third year. Median survival time was 689 days or 1.9 years post-collaring.

\section{Discussion}

\section{Population limitation of wolves}

The growth rate of the wolf population in the study area was limited from 1995-1998. The mean annual finite rate of increase, 0.96 , indicated a $4 \%$ rate of decline. This rate of increase is not unique, however, and similar rates recorded from other populations have varied from 0.93-2.40 (Theberge and Strickland 1978; Fritts and Mech 1981; Ballard et al. 1987; Hayes et al. 1991*; Messier 1991; Pletscher et al. 1997). 
In addition to the estimated rate of growth, there are a number of other factors that suggest the wolf population was declining slightly. First, pack sizes were small and generally declining. Mean pack size ( 3.5 wolves \pm SE 0.5) was much smaller than the average of 10 wolves for packs that hunt moose in North America (Mech 1970). Furthermore, five of seven packs in this study remained stable or declined in size from 1994 to 1998. If this population were increasing in size, the number of wolves within packs would likely increase. This happened in the Yukon where rapid increases in pack sizes of colonizing wolves were the primary means by which an intensively reduced wolf population reached their pre-reduction densities (Hayes and Harestad 2000).

High cumulative mortality of wolves is the second factor that suggested a declining population. We compared the cumulative rate of mortality from the first year $(32 \%)$ of our study with annual rates of mortality from other studies. There is little agreement among researchers on the annual rate of mortality that causes a population decline in wolves. However, Fuller (1989) reviewed several wolf studies across North America and concluded that populations would stabilize with an overall annual mortality rate of $35 \%$. Given this, it appears the mortality rate in this study was sufficient to account for the slightly declining rate of growth in this study.

Coupled with high mortality of adult wolves, low reproductive success of wolves in this study suggested a population decline. Wolves reproduced successfully in only $36 \%$ of possible occasions compared with 45-93\% noted in other areas (Messier 1985; Potvin 1987; Peterson et al. 1998; Hayes and Harestad 2000). We were unable to determine if wolves produced pups that died soon after birth or whether whelping occurred at all. Lack of denning, however, suggests no pups were produced.

\section{Limiting factors}

We examined the importance of two factors that limited the growth of the wolf population in this study: ungulate biomass and human-caused mortality. Ungulate biomass is commonly reported to limit growth of other wolf populations (Mech 1977a; Fuller and Keith 1980; Packard and Mech 1980; Keith 1983; Messier 1985; Peterson and Page 1988) and data from this study suggest it was important. The strongest data represented the occurrence of natural-caused mortality. In this study, more than half (9 of 17) of radiocollared wolves died from natural causes, which is high compared with other North American studies (Peterson 1977; Carbyn 1982; Peterson et al. 1984; Ballard et al. 1987; Hayes et al. 1991*). Starvation and intraspecific aggression were responsible for four of nine (24\%) wolves dead in this study and have been reported common in other populations where ungulate biomass is low. For instance, in southwestern Quebec,
Messier (1985) noted wolves with fewer prey available incurred more deaths from natural causes, namely starvation and intraspecific aggression. In that area, similar to our study area, moose density was 0.23 moose $/ \mathrm{km}^{2}$ and there were no other ungulate species present. Similarly, Mech (1977a) noted occurrence of starvation and intraspecific aggression increased as prey availability declined in Minnesota.

Disease was the other natural cause of death observed in this study. Four of nine wolves $(24 \%)$ died from either sarcoptic mange or blastomycosis. Blastomycosis is enzootic in Minnesota (Schlosser 1980) and Wisconsin (Sarosi et al. 1979; McDonough and Kuzma 1980) but until now (Krizan 2000; Paquet et al. 2001), had not been reported from other wolf populations across North America. This level of disease-related mortality has not been reported in any other populations of wolves. In other populations, disease accounts for $2-21 \%$ of wolf mortality (Carbyn 1982; Peterson et al. 1984; Fuller 1989; Ballard et al. 1997) and is often not even reported (Messier 1985; Ballard et al. 1987; Potvin 1987; Hayes et al. 1991*; Meier et al. 1995; Pletscher et al. 1997). The only other study where disease clearly affected a wolf population was in Alaska where rabies accounted for $21 \%$ of wolf mortality and was a significant factor in the decline of the population (Ballard et al. 1997). Disease cannot be linked with certainty to low ungulate biomass but wolves that lack food should be more vulnerable to disease than those with more food available. Furthermore, food shortage leading to nutritional stress could combine with disease factors to increase the significance of otherwise innocuous or sub-lethal conditions (Brand et al. 1995).

We also examined rates of consumption of ungulate prey to determine the importance of ungulate biomass as a limiting factor. Consumption rates for three of four packs in this study were low (Bremner River, Rein Lake, and White River). These packs consumed $<0.13 \mathrm{~kg} / \mathrm{kg}$ wolf/day, which Mech (1977b) determined is the minimum rate of consumption required for all wolves to survive and rear pups successfully. Two packs killed no ungulates and relied on scavenging to survive (White River and Rein Lake Packs).

These data suggest that at least three of four packs could have been limited by food. Indeed, in the White River Pack, the dominant female failed to reproduce the following spring and was extremely emaciated (mass $=23.5 \mathrm{~kg}$ ) when killed by other wolves later in the summer. Similarly, the Rein Lake Pack was reduced to one wolf by winter 1997. She did not reproduce the following summer and to survive, she scavenged mainly from the town dump for White River (Figure 2). She was dead as a result of mange by December 1998 (mass $=28.5 \mathrm{~kg}$ ). The Bremner River Pack may have been limited by food but data were not strong. One wolf dispersed in summer 1998 and died from unknown natural causes. Other wolves could have dis- 
persed and died later because pack numbers dropped from nine to three over the winter 1997-1998 (unpublished data). Some members of this pack, however, did survive and reproduce two years in a row.

Most of the rates of consumption in this study are similar to those from other areas where starvation and other signs of malnutrition of wolves were noted. For instance, Messier (1987) noted more deaths of wolves from malnutrition in areas of low density of moose $\left(0.23 \mathrm{moose} / \mathrm{km}^{2}\right)$ where wolves had $0.05 \mathrm{~kg} / \mathrm{kg}$ wolf/ day (based on kill rate of $1.7 \mathrm{~kg} /$ wolf/day and wolf mass of $32.3 \mathrm{~kg}$ ). Peterson and Page (1988) noted starvation and other indicators of severe nutritional stress in an area of high Moose density (1.9 moose/ $\mathrm{km}^{2}$ ) when food availability fell below $0.12 \mathrm{~kg} / \mathrm{kg}$ wolf/day (based on kill rate of $4.0 \mathrm{~kg} /$ wolf/day and wolf mass of $32.3 \mathrm{~kg}$ ).

As a final method to assess the importance of ungulate biomass, we examined density of Moose, the main prey for wolves in this study. Moose density was low to moderate $\left(0.153-0.285 \mathrm{moose} / \mathrm{km}^{2}\right)$ and similar to Moose densities in other areas where wolves were nutritionally stressed. Messier (1987) found that in areas where Moose density dropped below 0.4 moose $/ \mathrm{km}^{2}$, wolves were nutritionally stressed. He also reported that below 0.2 moose $/ \mathrm{km}^{2}$ wolf packs could not subsist and (or) reproduce successfully (Messier 1985).

The second limiting factor we examined was humancaused mortality. Besides ungulate biomass, it is the other most commonly reported factor that limits the growth of wolf populations (Gasaway et al. 1983; Keith 1983; Peterson et al. 1984; Fuller 1989; Noss et al. 1996; Paquet et al. 1996*). In other areas where human-caused mortality was considered the primary limiting factor, it accounted for $69-80 \%$ of all mortality (Peterson et al. 1984; Ballard et al. 1987, 1997). In our study area, human causes accounted for only $47 \%$ of mortality of adult radio-collared wolves. Nonetheless, human-caused mortality is likely still important, particularly given the low ungulate biomass and reproduction noted in this study. Gasaway et al. (1983) found that in areas with low ungulate biomass, harvest levels as low as $20 \%$ can limit wolf populations. Fuller (1989) found that wolf populations with low productivity can withstand less overall mortality because there are fewer pups, which often make up disproportionate amounts of harvests.

In conclusion, the population growth of wolves in this study area was limited and declined slightly based on (i) mean annual finite rate of increase; (ii) small and generally declining pack sizes; (iii) high cumulative mortality; and (iv) low reproductive success.

Based on these demographic patterns, low availability of ungulate biomass and existing levels of humancaused mortality, this population likely will remain at present low densities or continue to decline. This situation is challenging to managers for Parks Canada Agency because the study area, which includes a National
Park, may not have a highly productive source population for wolves. Further, protection for wolves outside the park is limited because few restrictions exist regarding the nature, timing, and extent of wolf harvesting.

\section{Acknowledgments}

Field research was funded by Parks Canada. We thank all PNP wardens and staff for field and technical support, particularly K. Wade, S. Sutton, and C. Strong. Additionally L. Parent provided much GIS expertise. Thanks also to J. Whittington and R. Whittington for field support and pilots W. Roberts and M. Robb for many safe hours of flying time. Thanks to Helicopter Wildlife Management Team for skillful capturing and collaring of animals. All animal treatment procedures were approved by the Wildlife Animal Care Committee, Ontario Ministry of Natural Resources (Permit Numbers 1994-13, 1995-13, 199613, 1997-13). We thank J. Whittington, B. Dobson, and M. Boyce who incisively reviewed later drafts of this manuscript. S.A. Forshner was personally supported by an NSERC scholarship, the University of Alberta, a University of Alberta Teaching Assistantship, Bill Samuel, and Parks Canada.

\section{Documents Cited (marked $*$ in text citations)}

Adorjan, A. S., and G. B. Kolenosky. 1969. A manual for identification of hairs of selected Ontario mammals. Ontario Department of Lands and Forests (Research Branch), Toronto, Ontario, Canada. 47 pages.

Burrows, F. G. M., P. Krizan, G. Neale, and P. Paquet. 1996. Interim report on the ecology of gray wolves and associated prey species in the Greater Pukaskwa Ecosystem, Ontario, 1994-1996. Parks Canada, Heron Bay, Ontario, Canada. 93 pages.

Gasaway, W. C., S. D. Dubois, D. J. Reed, and S. J. Harbo. 1986. Estimating moose population parameters from aerial surveys. Biological Paper 22. University of AlaskaFairbanks, Alaska, U.S.A. 108 pages.

Hayes, R. D., A. M. Baer, and D. G. Larsen. 1991. Population dynamics and prey relationships of an exploited and recovering wolf population in the southern Yukon. Yukon Fish and Wildlife Branch Final Report TR-91-1. 68 pages.

Kenward, R. E., and K. H. Hodder. 1996. RANGES V: An analysis system for biological data. Institute of Terrestrial Ecology, Dorset, U.K. 66 pages.

Paquet, P. C., J. Wierchowski, and C. Callaghan. 1996. Effects of human activity on gray wolves in the Bow River valley. Banff National Park, Banff, Alberta, Canada. 113 pages + maps

Poitevin, J., N. Lopoukhine, L. Rauke, D. Rivard, B. Ross, and J. Sparkes. 1989. Pukaskwa National Park resource description and analysis 1989. Hunter and Associates, Mississauga, Ontario, Canada. 427 pages.

Skibicki, A. 1994. Boundary analysis of the greater Pukaskwa National Park ecosystem using the $\mathrm{ABC}$ resource survey approach. University of Waterloo, Waterloo, Ontario, Canada. 92 pages.

Wade, K. D. 1993. Woodland caribou (Rangifer tarandus) census, Pukaskwa National Park. Parks Canada, Heron Bay, Ontario, Canada. 23 pages + appendix. 
Wade, K. D. 1995. Pukaskwa National Park and Ontario Ministry of Natural Resources, Wawa district woodland caribou (Rangifer tarandus) count. Parks Canada, Heron Bay, Ontario, Canada. 13 pages + appendices.

Wade, K. D. 1997. Pukaskwa National Park 1997 woodland caribou (Rangifer tarandus) count. Parks Canada, Heron Bay, Ontario, Canada. 12 pages + appendices.

Wade, K. D. 1999. Pukaskwa National Park 1999 woodland caribou (Rangifer tarandus) count. Parks Canada, Heron Bay, Ontario, Canada. 13 pages.

\section{Literature Cited}

Ballard, W. B., J. S. Whitman, and C. L. Gardner. 1987. Ecology of an exploited wolf population in south-central Alaska. Wildlife Monographs 98: 1-54.

Ballard, W. B., L. A. Ayres, P. R. Krausman, D. J. Reed, and S. G. Fancy. 1997. Ecology of wolves in relation to a migratory caribou herd in northwest Alaska. Wildlife Monographs 135: 1-47.

Bergerud, A. T. 1985. Antipredator strategies of caribou: dispersion along coastlines. Canadian Journal of Zoology 63: 1324-1329.

Bjorge, R. R., and J. R. Gunson. 1989. Wolf, Canis lupus, population characteristics and prey relationships near Simonette River, Alberta. Canadian Field-Naturalist 103: 327-334.

Brand, C. J., M. J. Pybus, W. B. Ballard, and R. O. Peterson. 1995. Infectious and parasitic diseases of the gray wolf and their potential effects on wolf populations in North America. Pages 419-429 in Ecology and conservation of wolves in a changing world. Edited by L. N. Carbyn, S. H. Fritts, and D. R. Seip. Canadian Circumpolar Institute, Edmonton, Alberta, Canada.

Burrows, F. G. M. 2001. The effects of landscape disturbance on the population dynamics and behaviour of moose (Alces alces) in the Greater Pukaskwa Ecosystem, Ontario. M.Sc. thesis, Lakehead University, Thunder Bay, Ontario, Canada. 86 pages + appendices.

Carbyn, L. N. 1982. Incidence of disease and its potential role in the population dynamics of wolves in Riding Mountain National Park, Manitoba. Pages 106-116 in Wolves of the world: perspectives of behaviour, ecology, and conservation. Edited by F. H. Harrington and P. C. Paquet. Noyes Publications, Park Ridge, New Jersey, U.S.A.

Ciucci, P., L. Boitani, F. Francisci, and G. Andreoli. 1997. Home range, activity, and movements of a wolf pack in central Italy. Journal of Zoology (London) 243: 803-819.

Forbes, G. J., and J. B. Theberge. 1996. Response by wolves to prey variation in central Ontario. Canadian Journal of Zoology 74: 1511-1520.

Fritts, S. H., and L. D. Mech. 1981. Dynamics, movements, and feeding ecology of a newly protected wolf population in northwestern Minnesota. Wildlife Monographs 80: $1-79$.

Fuller, T. K. 1989. Population dynamics of wolves in northcentral Minnesota. Wildlife Monographs 105: 1-41.

Fuller, T. K., and L. B. Keith. 1980. Wolf population dynamics and prey relationships in northeastern Alberta. Journal of Wildlife Management 44: 583-602.

Gasaway, W. C., R. O. Stephenson, J. L. Davis, P. E. K. Shepherd, and O. E. Burris. 1983. Interrelationships of wolves, prey, and man in interior Alaska. Wildlife Monographs $84: 1-50$.
Hayes, R. D., and A. Harestad. 2000. Demography of a recovering wolf population in the Yukon. Canadian Journal of Zoology 78: 36-48.

Keith, L. B. 1983. Population dynamics of wolves. Pages 66-77 in Wolves in Canada and Alaska: Their Status, Biology and Management. Edited by L. N. Carbyn. Canadian Wildlife Service Report Series Number 45.

Kolenosky, G. B. 1972. Wolf predation on wintering deer in east-central Ontario. Journal of Wildlife Management 36: 357-369.

Kolenosky, G. B., and D. H. Johnston. 1967. Radio-tracking timber wolves in Ontario. American Zoologist 7: 289303.

Krizan, P. 1997. The effects of human development, landscape features, and prey density on the spatial use of wolves (Canis lupus) on the north shore of Lake Superior. M.Sc. thesis, Acadia University, Wolfville, Nova Scotia, Canada. 109 pages.

Krizan, P. 2000. Blastomycosis in a free-ranging lone wolf, Canis lupus, on the north shore of Lake Superior 114: 491-492.

McDonough, E. S., and J. F. Kuzma. 1980. Epidemiological studies on blastomycosis in the state of Wisconsin. Sabouraudia 18: 173-183.

Mech, L. D. 1970. The wolf: ecology and behaviour of an endangered species. Natural History Press, New York, New York, U.S.A. 384 pages.

Mech, L. D. 1977a. Productivity, mortality, and population trends of wolves in northeastern Minnesota. Journal of Mammalogy 58: 559-574.

Mech, L. D. 1977b. Population trend and winter deer consumption in a Minnesota wolf pack. Pages 55-74 in Proceedings of 1975 predator symposium. Edited by R. L. Phillips and C. Jonkel. University of Montana, Missoula, Montana, U.S.A.

Meier, T. J., J. W. Burch, L. D. Mech, and L. G. Adams. 1995. Pack structure and genetic relatedness among wolf packs in a naturally-regulated population. Pages 293-302 in Ecology and conservation of wolves in a changing world. Edited by L. N. Carbyn, S. H. Fritts, and D. R. Seip. Canadian Circumpolar Institute, Edmonton, Alberta, Canada.

Messier, F. 1984. Moose-wolf dynamics and the natural regulation of moose populations. Ph.D. dissertation, University of British Columbia, Vancouver, British Columbia, Canada. 143 pages.

Messier, F. 1985. Social organization, spatial distribution, and population density of wolves in relation to moose density. Canadian Journal of Zoology 63: 1068-1077.

Messier, F. 1987. Physical condition and blood physiology of wolves in relation to moose density. Canadian Journal of Zoology 65: 91-95.

Messier, F. 1991. The significance of limiting and regulating factors on the demography of moose and white-tailed deer. Journal of Animal Ecology 60: 377-393.

Mohr, C. O. 1947. Table of equivalent populations of North American small mammals. American Midland Naturalist 37: 223-249.

Noss, R. F., H. B. Quigley, M. G. Hornocker, T. Merrill, and P. P. Paquet. 1996. Conservation biology and carnivore conservation in the Rocky Mountains. Conservation Biology 10: 949-963. 
Okarma, H., W. Jedrzejewski, K. Schmidt, S. Sniezko, A. N. Bonevich, and B. Jedrzejewska. 1998. Home ranges of wolves in Bialowieza Primeval Forest, Poland, compared with other Eurasian populations. Journal of Mammalogy 79: 842-952.

Packard, J. M., and L. D. Mech. 1980. Population regulation in wolves. Pages 35-150 in Biosocial mechanisms of population regulation. Edited by M. N. Cohen, R. S. Malpass, and H. G. Klein. Yale University Press, New Haven, Connecticut, U.S.A.

Paquet, P. C., F. Burrows, A. Forshner, G. Neale, and K. Wade. 2001. Blastomysosis in a free-ranging lone wolf, Canus lupus, on the north shore of Lake Superior, Ontario - a response to P. Krizan. Canadian Field-Naturalist 115: 185.

Parks Canada. 2000. Canada National Parks Act. Government of Canada, Ottawa, Ontario, Canada.

Peterson, R. O. 1977. Wolf ecology and prey relationships on Isle Royale. United States National Park Service Scientific Monograph Series 11. 210 pages.

Peterson, R. O., J. D. Woolington, and T. N. Bailey. 1984. Wolves of the Kenai Peninsula, Alaska. Wildlife Monographs 88: 1-52.

Peterson, R. O., and R. E. Page. 1988. The rise and fall of Isle Royale wolves, 1975-1986. Journal of Mammalogy 69: 89-99.

Peterson, R. O., N. J. Thomas, J. M. Thurber, J. A. Vecetich, and T. A. Waite. 1998. Population limitation and the wolves of Isle Royale. Journal of Mammalogy 79: 828-841.

Pimlott, D. 1967. Wolf predation and ungulate populations. American Zoologist 7: 267-278.

Pletscher, D. H., R. R. Ream, D. K. Boyd, M. W. Fairchild, and K. E. Kunkel. 1997. Population dynamics of a recolonizing wolf population. Journal of Wildlife Management 61: 459-465.

Potvin, F. 1987. Wolf movements and population dynamics in Papineau-Labelle reserve, Quebec. Canadian Journal of Zoology 66: 1266-1273.

Rausch, R. A. 1967. Some aspects of the population ecology of wolves, Alaska. American Zoologist 7: 253-265.

Sarosi, G. A., M. R. Eckman, S. F. Davies, and W. K. Laskey. 1979. Canine blastomycosis as a harbinger of human disease. Annals of Internal Medicine 91: 733-735.

Schlosser, W. D. 1980. Canine blastomycosis in Minnesota. M.Sc. Thesis, University of Minnesota, Minneapolis, Minnesota, U.S.A. 54 pages.

Theberge, J. B., and D. R. Strickland. 1978. Changes in wolf numbers, Algonquin Provincial Park, Ontario. Canadian Field-Naturalist 92: 395-398.

Thurber, J. M., and R. O. Peterson. 1993. Effects of population density and pack size on the foraging ecology of gray wolves. Journal of Mammalogy 74: 879-889.

Received 13 March 2003

Accepted 1 March 2004 